\title{
Observations on the Protoplasts of Fusarium culmorum and on their Fusion
}

\author{
By F. LOPEZ-BELMONTE, I. GARCIA ACHA AND \\ J. R. VILLANUEVA \\ Instituto de Biología Celular, CSIC, Velázquez, 138, Madrid-6, Spain
}

(Received 14 February 1966)

\section{SUMMARY}

Some characteristics of protoplast extrusion from hyphae of Fusarium culmorum are described. One, two or more protoplasts might be released from one mycelial compartment. The release was stimulated by controlled dilution of the stabilizing solution. $\mathrm{NH}_{4} \mathrm{Cl}$ and mannitol were the best stabilizers of those tested. Connecting threads between protoplasts were observed; their meaning is discussed. Changes in the growth medium did not affect mycelium sensitivity for protoplast formation. Various stages of a protoplast fusion process were followed. Protoplast fusion usually began by an attraction of two bodies followed by junction and fusion to give a single large body. There was no evidence that these fusions represent a sexual process. Fusion of protoplasts in Fusarium is infrequent.

\section{INTRODUCTION}

The formation and development of spherical forms called protoplasts have been described for a few filamentous fungi: Neurospora crassa (Emerson \& Emerson, 1958; Bachman \& Bonner, 1959), Fusarium culmorum (Rodriguez Aguirre \& Villanueva, 1963; Rodriguez Aguirre, García Acha \& Villanueva, 1964; García Acha, Lopez-Belmonte \& Villanueva, 1966) and Polystictus versicolor (Strunk, 1964). Transformation of mycelial cells into protoplasts under the influence of a cell-wall lysing enzyme called strepzyme RA was obtained with a large number of other fungi (Rodriguez Aguirre, García Acha \& Villanueva, 1963). Striking differences in the rate and the proportion of protoplast formation among different species were observed. The purpose of the present paper is to report a more detailed description of the formation and subsequent development of the spherical protoplast bodies from $F$. culmorum, including the phenomenon of protoplast fusion.

\section{METHODS}

Organisms and cultural conditions. The organism chiefly used in this investigation was Fusarium culmorum CECT no. 2148, but other fusarium species were also used. Maintenance of the stock cultures and growth conditions were as described by Rodriguez Aguirre et al. (1964).

Source of the lytic enzymes and estimation of activity. The preparation of cell-wall lysing enzyme from Streptomyces $\mathbf{R A}$ and the estimation of activity were as previously reported (Rodriguez Aguirre et al. 1964).

Preparation of protoplasts. Young mycelium was harvested by centrifugation, 
washed with distilled water and stored as a thick suspension at $4^{\circ}$. Usually fresh mycelium was employed. For the preparation of protoplasts, intact mycelium (equiv. $5 \mathrm{mg}$. dry wt./ml.) was suspended in a solution (usually $0.8 \mathrm{M}$-mannitol), and incubated for two or more hours with a lytic enzyme preparation from Streptomyces RA (strepzyme RA; Rodriguez Aguirre et al. 1964) with gentle agitation. Samples were taken from time to time for observation in the phase-contrast microscope. Protoplasts were liberated in $20-30 \mathrm{~min}$. depending on the activity and concentration of the lytic enzyme preparation. Protoplasts sometimes appeared earlier when $\mathrm{NH}_{4} \mathrm{Cl}$ was used as stabilizer. This particular system contained only $0.8 \mathrm{M}-\mathrm{NH}_{4} \mathrm{Cl}$ solution, enzyme and mycelium. Its main advantage was the greater yield of protoplasts, being nearly double that obtained with mannitol or other stabilizers. Protoplast forms appeared as high contrast structures in phase-contrast microscopy; they were stable for more than $24 \mathrm{hr}$ under the conditions of preparation, but at $5^{\circ}$ lasted for several weeks.

\section{RESULTS}

\section{The release of protoplasts}

Before the release of protoplasts the hypha swells at certain points, presumably of greatest sensitivity to the enzymic attack. Then the protoplast emerges, at first as a small round bud-like structure at one side or at one end of a broken hypha. This bud increases in size relatively rapidly at the expense of the mycelium contents, which simultaneously decrease in size. The protoplasmic content of the hyphal compartment is eventually incorporated into one large body. Nothing, or only a small portion of the protoplasmic contents, remains inside the mycelium. Less frequently, the extrusion of one spherical body is followed by another of the same size connected to the first one by a thin thread. Two pores can be formed in the cell wall of the same hyphal compartment, but as a rule only one is formed. The length of time required for one or two spherical bodies to be formed varies with the concentration of the enzyme and the incubation conditions. In general, protoplasts were not released slowly and gradually, but suddenly and in steps. Physical forces may help this liberation. When the incubation mixture was diluted with water just at the moment when protoplasts started to form, the liberation of protoplasts took place much more quickly. Changes in osmotic conditions apparently helped in the extrusion of the protoplasts.

The evolution of protoplast liberation from a single compartment in the mycelium was followed with the microscope in hanging drop preparations. Figure 1 shows diagrammatically the stages of protoplast formation when originating from one compartment between two septa. The contents pass out through one pore formed in the hyphal cell wall. On several occasions we watched the cytoplasmic contents pass through the septal pore. It is easy to see the thin thread connecting the contents of two neighbouring cells (Pl. 1, fig. I). We have also seen these threads in the branching of the mycelium. The thread was not homogenous but sometimes included small spherical enlargements. It was possible sometimes to see two of these little structures, one on each side of the septum. These globules may be small structures of the cytoplasm, retained inside the extended membranes.

Not all hyphae were equally sensitive to lytic enzyme attack. Age may have been 
one reason for this, but probably not the only one, since we were normally using very young mycelium (18 hr). However, after incubation for 2 days with enzyme the whole mycelium was degraded to small pieces.
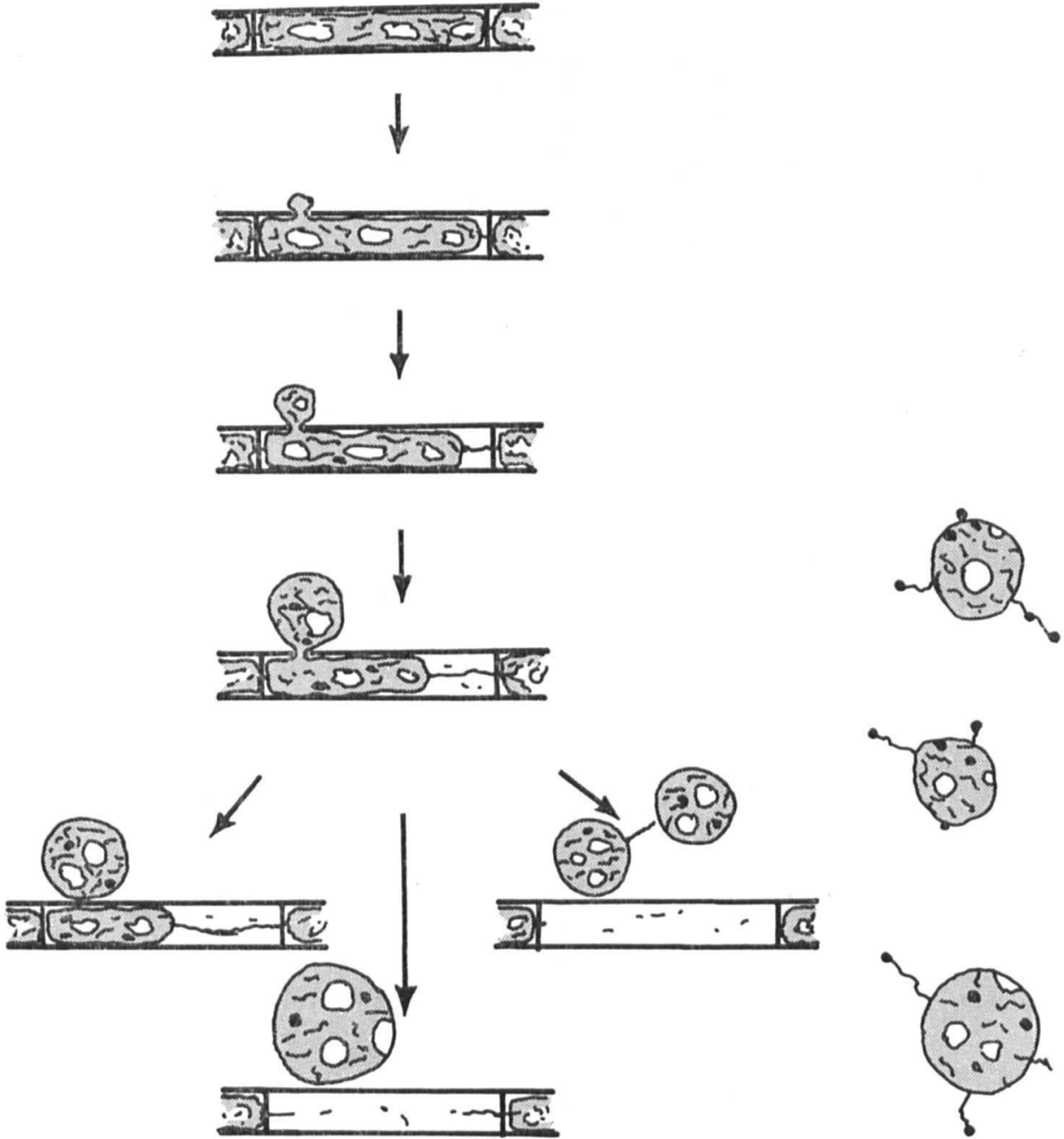

Fig. 1

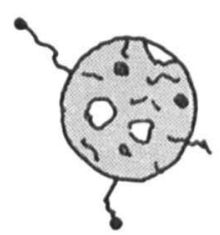

Fig. 2

Fig. 1. Diagrammatic representation of the various stages of protoplast release in Fusarium culmorum.

Fig. 2. Diagram of protoplasts with adhering 'satellites'.

\section{Phase-contrast appearance of the protoplasts and residues}

The protoplasts were not uniform; they were of different sizes and appearances. Some of them were refractile and others were quite dark, very grey but more transparent and appeared to be more fragile (Pl. 1, fig. 2). However, there were no noticeable differences to osmotic shock.

The contents of the protoplasts were also not uniform. The number of vacuoles 
and other internal structures varied greatly and was largely influenced by the conditions used for the growth of the fungus. Some of the protoplasts had one very large vacuole or several vacuoles, whereas others had none or they were very small (Pl. 1, fig. 3). The external aspect of the protoplasts also varied, in good agreement with the very different appearances of the hyphae. It was observed that gentle heating caused the protoplasts to burst the containing membrane, releasing the protoplasmic contents; a vacuole would remain more or less intact and unaltered (Pl. 1, fig. 4). Observations by using specific nuclear stains and fluorescent microscopy suggested that most of the protoplasts contained only one nucleus, although some may have had two or more.

Some of the protoplasts showed very clearly what we call 'satellites', that is, very small, generally dark, spheres attached to the protoplasts by thin threads of different sizes (Fig. 2). They might be the remains of threads connecting protoplasts which had broken; but some protoplasts had three or more of these satellites. We also observed in several cases that after the liberation of protoplasts, the respective hypha was not completely empty, as might have been the case once the cellular contents had been extruded, but there remained inside the digested cell wall small spheres similar in size and appearance to the so-called satellites (Pl. 2, fig. 5).

In a hypotonic medium the protoplasts might increase in volume up to three times their original size; their appearance also changed. The membrane became almost invisible under the phase-contrast microscope, the cytoplasmic content was less refractile, and the internal structures were more evident. After incubation for several days in the medium where the protoplasts were formed, a considerable number of them are not digested by the lytic enzyme present. In some cases, however, the protoplasts were crenated and lost their spherical shape.

After long incubation, the hyphae were extensively digested and showed big pores or holes all along the wall. The septa, however, were much less attacked by the lytic enzyme, and could be seen free in the medium or united to the remains of the attacked hyphal walls (Pl. 2, fig. 6).

\section{Effect of the stabilizing substances}

Several osmotic stabilizers were used, all at 0.6 $\mathrm{m}$ concentration, for the formation of protoplasts from fusarium mycelium. Xylose, sucrose and maltose allowed the formation of only a small number of protoplasts; fructose and sorbose were intermediate; the best results were obtained with $\mathrm{NH}_{4} \mathrm{Cl}$, mannitol, $\mathrm{NaCl}$ or rhamnose. Negative results were obtained with $\mathrm{Na}_{2} \mathrm{CO}_{3}, \mathrm{NaH}_{2} \mathrm{PO}_{4}$ and $\left(\mathrm{NH}_{4}\right)_{2} \mathrm{SO}_{4}, \mathrm{HN}_{4} \mathrm{NO}_{3}$ and $\mathrm{KNO}_{3}$ gave better results and $\mathrm{KCl}$ gave the same yield of protoplasts as mannitol. The $\mathrm{NH}_{4} \mathrm{Cl}$, however, gave much better results, and in a shorter time. The $\mathrm{pH}$ values may have been responsible for some of these effects. The stability of the protoplasts was markedly affected by the reaction of the suspending medium; the optimum for stability was $\mathrm{pH}$ 6-8.

The effect of stabilizers at several concentrations was studied. As a rule protoplasts burst at $0 \cdot 1 \mathrm{M}$ concentration, but with $\mathrm{KNO}_{3}, \mathrm{NaCl}$ and $\mathrm{MgCl}_{2}$ complete breakage was obtained at $0.05 \mathrm{M}$. When glycine or urea was used as stabilizer, the protoplasts are well stabilized at $1.5 \mathrm{M}$ concentration, but at $1.0 \mathrm{M}$ nearly all the protoplasts lysed. The phenonemon in this case may have been due to a direct effect on the membrane rather than to osmotic pressure. At the critical osmotic point the 
protoplasts burst slowly, liberating the internal contents. At this stage the membrane was broken at one or more places and sometimes several internal structures remained within. Often the vacuoles remained visible in the medium for a long time before they burst, under these osmotic conditions.

The stability of the protoplasts was affected not only by the stabilizer used but also by the concentration of the medium in which the fungus was grown (Villanueva, 1966).

\section{Effect of alterations in the composition of the growth medium}

Cultural conditions may affect the sensitivity of cell walls to lytic enzymes, and changes in the composition of the growth medium may affect the composition of the cell walls. Dunwell, Ahmad \& Rose (1961) suggested that growth conditions markedly affected the polysaccharide composition of fungal walls. Holter \& Ottolenghi (1960) reported that the substitution of melibiose for glucose in the growth medium of a saccharomyces markedly affected its susceptibility to the action of lytic enzyme from snail. This may be explained by the building of a different type of polysaccharide in the cell wall of the yeast.'

The effect of the carbon source in the growth medium of Fusarium culmorum on the susceptibility of the mycelium to the lytic enzyme was examined. No differences in the ability to release protoplasts were found when the glucose of the medium was replaced by fructose, galactose, mannose or sorbose at the same concentration.

\section{Susceptibility of different fusarium species to the strepzyme $R A$}

After preliminary trials with Fusarium culmorum other species of the same genus were tested for their susceptibility to strepzyme RA for obtaining protoplasts. No significant differences from those described above were found with: $F$. oxysporum, $F$. avenaceum, $F$. equisetibulletum, $F$. scirpi, $F$. moniliforme, $F$. pomae, $F$. sporotrichiodes, $F$. tumidum, $F$. solani, $F$. cubense, $F$. roseum, $F$. semitectum var. majus, $\boldsymbol{F}$. sambucinum, $\boldsymbol{F}$. poae.

\section{Fusion of protoplasts}

Protoplasts of Fusarium culmorum prepared by the digestion of the cell wall with the lytic enzyme preparation strepzyme RA (Rodriguez Aguirre et al. 1964) were observed to fuse. The frequency of this was very low and the whole process took less than 2 min. Direct continuous observations leave no doubt that fusion does occur. Plate 2, fig. 7 illustrates various stages of the fusing process. Owing to difficulties of resolution the details of union have not been seen within living fusarium protoplasts. The various stages of the process of fusion of protoplasts leave no doubt that the larger protoplasts thereby derived are complex forms. The principal conclusion at present is that fusion of fusarium protoplasts can take place and that the resulting form remains viable. Although the actual process of fusion may vary somewhat from case to case, each has in common the union of two spherical protoplasts. Protoplast fusion in F. culmorum usually occurs between two bodies which seem to be connected by a thin nearly invisible filament. Occasionally the filaments had some enlargements in the form of granules (Pl. 2, fig. 8). Their relative positions probably represented sister protoplasts from one mycelial compartment, although the possibility cannot be excluded that fusion may occur between bodies from 
different compartments which become connected after release from the mycelium. Sometimes several protoplasts were connected by one thread (Pl. 2, fig. 9).

Practically nothing is known of the behaviour of the cell contents during or after protoplast fusion which results in the formation of a larger body. The spherical forms produced in this way have not been seen to develop further.

With the phase-contrast microscope it was observed that the vacuoles of the protoplasts after fusion remained unaltered and spherical, and some of the cytoplasmic elements appeared as dark as in the individual units. In general the resolution of structures within each of the fusing protoplasts was difficult. Although we earlier described the presence of cytoplasmic membrane enveloping each protoplast (Rodriguez Aguirre et al. 1964), phase-contrast microscopy of the fused protoplasts showed protuberances on the cell surface, mainly corresponding to the vacuoles. This is clear in the micrographs of the last stages of the fusing process (Pl. 2, fig. 7). The possibility cannot be neglected that fusion of free masses of protoplasm previously released into the suspending medium may take place. However, our experience with protoplasts, together with the fact that attempts to produce the fusing bodies by plasmolysis of the protoplasts has produced only negative results, speak in favour of fusion of true protoplasts.

The fusion of protoplasts of Fusarium culmorum was not very common under our experimental conditions. The physical properties of the environment may play a role in the fusion. We do not know whether the large bodies are able to develop by division or rupture. Some of these fused bodies do not develop and may remain apparently unchanged during a $6 \mathrm{hr}$ period of observation. Some fused bodies undergo lysis and this may be preceded by increase in size as a consequence of water penetration. The lysis occurs suddenly and leaves only traces of cell body. Attempts to isolate a fused body with the help of the micromanipulator and to cultivate it have thus far been unsuccessful.

\section{DISCUSSION}

Much doubt has been expressed in the past in our laboratory about the fusion phenomenon with protoplasts. Strunk (1966) reported that protoplasts of Polystictus versicolor could fuse under appropriate conditions, two coalescing to form a larger sphere; the whole process was shown micro-cinematographically. As far as we are aware, no other reports of fusion of fungal protoplasts have appeared. The fusion of two protoplasts to form a larger body may be a consequence of the union between two spherical entities by visible filaments. It remains to be seen whether fusion can be produced between protoplasts arising from different hyphal compartments and lacking any connecting filaments. Fusion between protoplasts of $\boldsymbol{P}$. versicolor seems chiefly to be a consequence of the attraction between spherical bodies joined by threads (Strunk, 1966). In this organism time-lapse cinematography showed a high frequency of fusion and the phenomenon was chiefly attributed to the presence of the connecting filaments. In the present work with Fusarium culmorum, however, no fused bodies were seen to form when protoplasts were suspended in stabilizers other than mannitol solution.

Large body formation with fusarium protoplasts appears to be primarily a physical phenomenon. No evidence of what happens to the enveloping membranes of the individual protoplasts is available. Whether the formation of a large body may 
be interpreted as a sexual process is also unknown. Our impression is that the phenomenon is the result of some physical attraction, but it is difficult to tell whether the membrane exists as an independent entity in the mycelial cell. Evidence in other systems suggests that elasticity and versatility of the plasma membranes, mainly in the plant cells, exist (Dr D. H. Northcote, private communication). Whether the fused bodies are capable of reversion to form new mycelium, as already shown with isolated protoplasts of Fusarium culmorum (García Acha, LopezBelmonte \& Villaneuva, to be published), remains to be seen. It has not been observed microscopically and direct observation of such reversion is essential. None of the results obtained in the present work yielded sufficient information to postulate a significance for the fused forms. Strunk (1966) considered the formation of fused bodies with Polystictus versicolor to be a natural phenomenon occurring during the process of protoplast formation.

\section{REFERENCES}

Bachmann, B. J. \& Bonner, D. M. (1959). Protoplasts from Neurospora crassa. J. Bact. 78, 550 .

Dunwell, J. L., Ahmad, F. \& Rose, A. H. (1961). Changes in the polysaccharide composition of yeast resulting from biotin deficiency. Biochim. biophys. Acta 51, 604.

Emerson, S. \& Emerson, M. R. (1958). Production, reproduction and reversion of protoplast-like structures in the osmotic strain of Neurospora crassa. Proc. natn. Acad. Sci. U.S.A. 44, 668.

García Acha, I., Lopez-Belmonte, F. \& Villanueva, J. R. (1966). Preparation of protoplast-like structures from conidia of Fusarium culmorum. Antonie van Leeurvenhoek (in the Press).

Holter, H. \& Ottolenghi, P. (1960). Observations on yeast protoplasts. C. r. Trav. Lab. Carlsberg 31, 409.

Rodriguez Aguirre, M. J. \& Villanueva, J. R. (1962). Production of protoplast-like structures from various species of fungi. Nature, Lond. 196, 693.

Rodriguez Aguirre, M. J., García Acha, I. \& Villanueva, J. R. (1963). An enzyme from a Streptomyces sp. to prepare mould 'protoplasts'. Experientia 19, 82.

Rodriguez Aguirre, M. J., García Acha, I. \& Villanueva, J. R. (1964). Formation of protoplasts of Fusarium culmorum by strepzyme. Antonie van Leeureenhoek 30, 33.

Strunk, Ch. (1964). Zur Wirkung von Schneckenenzym auf die Zellwand von Polystictus versicolor. 3rd European Regional Conference on Electron Microscopy, p. 143, Prague: Publishing House of the Czechoslovak Academy of Sciences.

Strunk, Cr. (1966). Entstehung und Reversion von Basidiomyceten-Protoplasten. Symposium über Hefe-Protoplasten, Jena, 1965, Berlin: Akademie-Verlag.

Villanueva, J. R. (1966). Protoplasts of fungi. In The Fungi. Ed. by G. C. Ainsworth and A. S. Sussman. Vol. 2, p. 1. New York: Academic Press. 


\section{F. Lopez-Belmonte, I. García ACha and J. R. Villanueva \\ EXPLANATION OF PLATES \\ Plate 1}

Fig. 1. Phase-contrast micrograph showing thread connecting the cytoplasmic contents of the hyphae $(\times 6000)$.

Fig. 2. Purified suspension of fusarium protoplasts; extent of contaminating mycelium showing the great variability in sizes and appearance $(\times 6000)$.

Fig. 3. Protoplasts of Fusarium culmorum showing vacuoles of different sizes $(\times 6000$ and $\times 8000)$. Fig. 4. Burst protoplasts of $F$. culmorum releasing the vacuoles $(\times 6000)$.

\section{Plate 2}

Fig. 5. Micrograph showing empty hypha with remaining granular materials $(\times 6000)$.

Fig. 6. Remnants of fusarium mycelium after protoplasts have been released. Note the intact septa. $(\times 6000)$.

Fig. 7. Phase contrast micrograph of various stages of the fusing process of Fusarium culmorum protoplasts $(\times 6000)$.

Fig. 8. Micrograph showing filaments connecting protoplasts $(\times 6000)$.

Fig. 9. Various protoplasts of $F$. culmorum connected by threads $(\times 4000)$. 

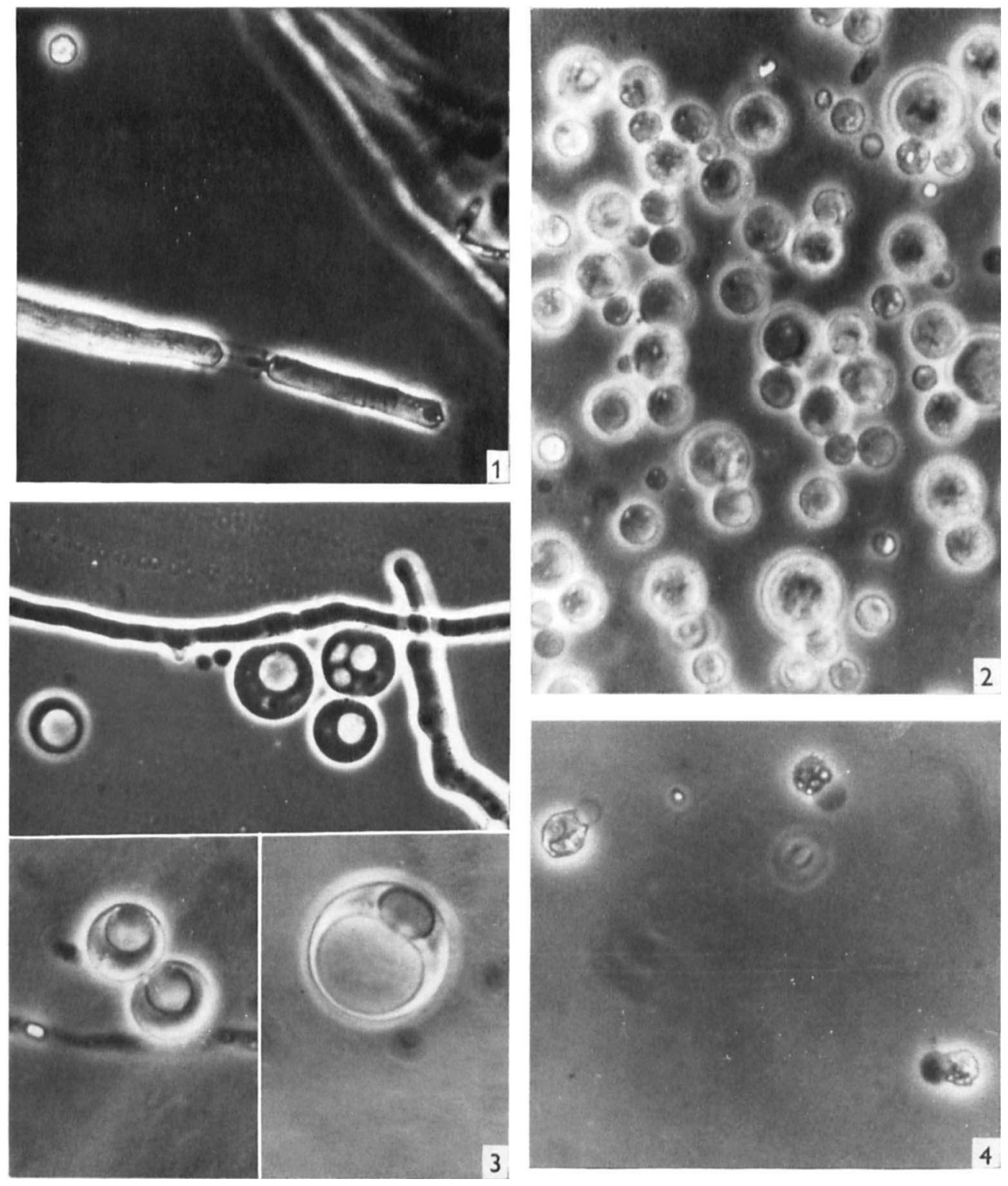

F. LOPEZ-BELMONTE, I. GARCÍA ACHA AND J. R. VILLANUEVA

(Facing p. 134) 

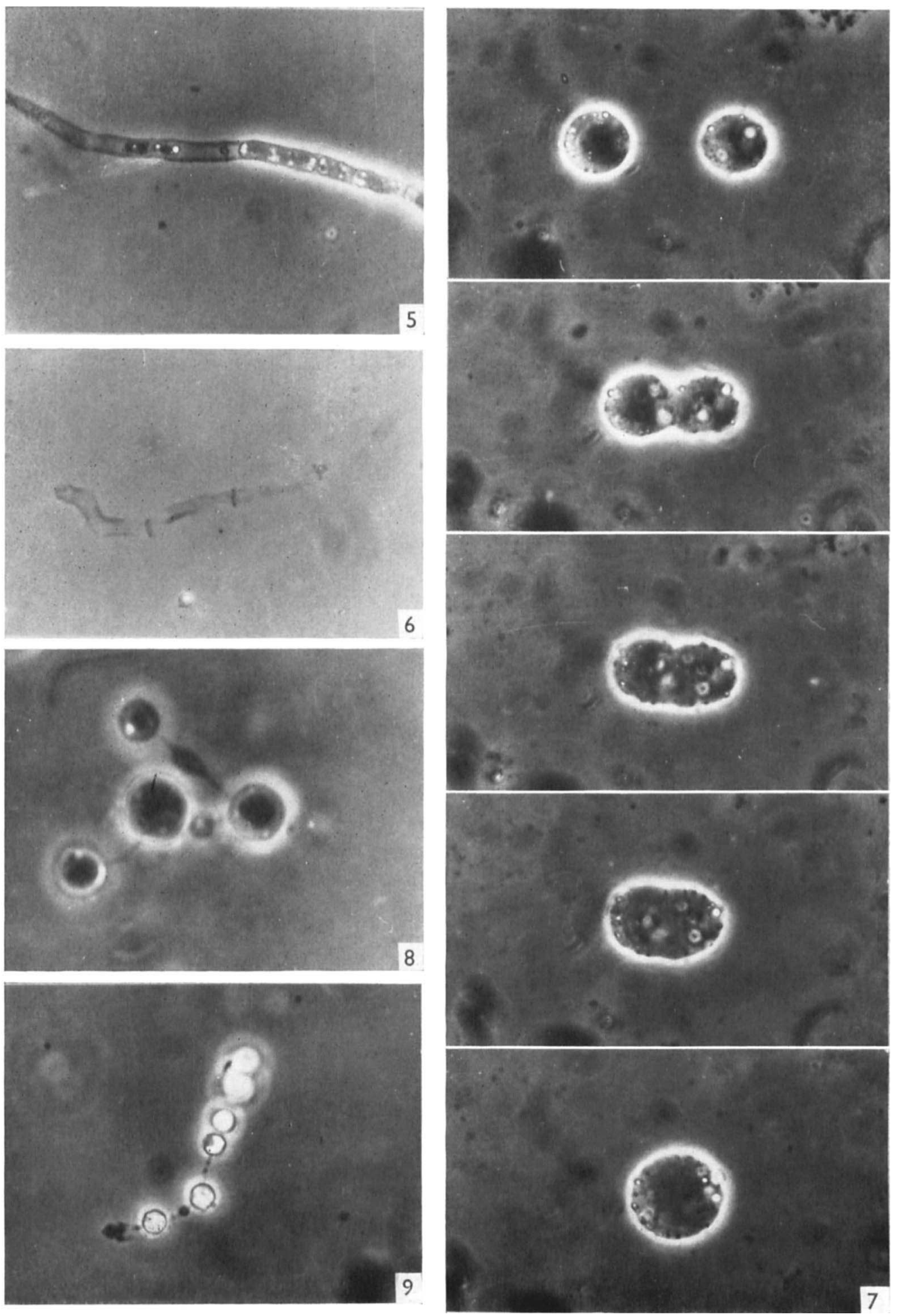

F. LOPEZ-BELMONTE, I. GARCIA ACHA AND J. R. VILLANUEVA 